\title{
LA HISTORIA ENTRE LA LIBERTAD Y LA DERROTA. LA GENERACIÓN POSREVOLUCIONARIA EN HEREJES DE LEONARDO PADURA
}

\author{
POR \\ José Martínez Rubio \\ Università di Bologna
}

\section{Neopolicial y literatura social en Leonardo Padura}

El éxito de Leonardo Padura ha tenido efectos paralelos tanto en el interior de la isla como en el exterior. Quizás por ese éxito rotundo, las novelas del autor cubano han sido acogidas con mucha expectación en Europa y en el resto de América Latina en cuanto que son capaces de ofrecer una nueva representación de la realidad cubana, alejada de estereotipos políticos o periodísticos sobre los avatares cotidianos de la Revolución, y superando otras narrativas anteriores que remiten a contextos históricos distintos (Reinaldo Arenas, Virgilio Piñera, Lezama Lima o Guillermo Cabrera Infante, por citar a los ya clásicos). La concesión del Premio Princesa de Asturias de las Letras en el año 2015 confirmó, a nivel institucional, el éxito que ya obtuviera entre crítica y público desde años atrás.

Leonardo Padura escoge el genero policial para vehicular ese nuevo retrato de $\mathrm{La}$ Habana. La representación de la ciudad y de la vida de los habaneros se vale de este género que se adentra prototípicamente en los espacios del crimen, de la delincuencia, de la corrupción o de la perversión, es decir, de todo aquello que se encuadra en el marco de lo prohibido y de lo perseguido por la ley. No en vano, el nacimiento del género policial en la Modernidad (Resina) coincide con el desarrollo industrial y económico de las grandes capitales europeas y actúa como relato paralelo a esa senda ascendente que marca la idea de progreso, evidenciando los conflictos de la nueva forma de vida moderna y retratando la parte oscura de las ciudades en expansión. Como explicaría Marshall Berman en su célebre estudio sobre la Modernidad, el ser moderno entrañaría una contradicción intrínseca: al tiempo que las sociedades modernas operan un proceso de desarrollo de posibilidades económicas (para la sociedad) y vitales (para el sujeto), operan al mismo tiempo un desarrollo de peligros hasta el momento desconocidos que amenazan con destruir todo ese mundo nuevo:

La vorágine de la vida moderna ha sido alimentada por muchas fuentes: los grandes descubrimientos en las ciencias físicas, que han cambiado nuestras imágenes del 
universo y nuestro lugar en él; la industrialización de la producción, que transforma el conocimiento científico en tecnología, crea nuevos entornos humanos y destruye los antiguos, acelera el ritmo general de la vida, genera nuevas formas de poder colectivo y de lucha de clases; las inmensas alteraciones demográficas, que han separado a millones de personas de su hábitat ancestral, lanzándolas a nuevas vidas a través de medio mundo; el crecimiento urbano, rápido y a menudo caótico; los sistemas de comunicación de masas, de desarrollo dinámico que envuelven y unen a las sociedades y pueblos más diversos, los Estados cada vez más poderosos, estructurados y dirigidos burocráticamente, que se esfuerzan constantemente por ampliar sus poderes; los movimientos sociales masivos de personas y pueblos, que desafían a sus dirigentes políticos y económicos y se esfuerzan por conseguir cierto control sobre sus vidas; y finalmente, conduciendo y manteniendo a todas estas personas e instituciones un mercado capitalista mundial siempre en expansión y drásticamente fluctuante. (1-2)

Desde el siglo XIX, la novela policial, junto a la novela de terror y otros géneros, se enfrentaría desde la ficción a esos peligros y esas amenazas que comportan todo desarrollo económico y científico. En esa nueva vida urbana moderna se resignificarán los conceptos de orden y de libertad, y se regulará toda conducta social a través de la Ley, que trazará una frontera nítida entre legalidad e ilegalidad. El policial, en última instancia, vendría a hablar esa parte oculta de las sociedades industriales, hoy ya posindustriales, a la vez que exploraría por un lado conflictos sociales nuevos, derivados del desarrollo económico, de la marginalidad económica o de la expansión urbana con su tensión entre centro y periferia, y por otro pulsiones de una nueva subjetividad que se enfrenta a un nuevo contexto vital y social.

Andando el siglo XX y adentrándonos en el XXI, algunos estudios ya observaron la potencialidad del género policial a la hora de elaborar una representación de la vida contemporánea y sus conflictos, y vieron cierta expansión más allá de sus esquemas prototípicos hacia la novela social.

La novela negra, aparte de ser prácticamente el único género literario que en la actualidad permite desarrollar novela social, es el más adecuado para abordar determinadas temáticas: el terrorismo, las corrientes migratorias, la violencia contra la mujer, la corrupción en todas sus formas, la delincuencia organizada, los crímenes de Estado, y en definitiva el horror del hombre ante el convulso mundo del siglo XXI. A veces incluso desde unos planteamientos a los que no pueden llegar el ensayo o la divulgación. (Arjona)

Tal consideración del policial como escritura reveladora de las problemáticas sociales y no como mero juego intelectual entre verdad y misterio, criminal e investigador, serviría como complemento a la crónica periodística, si bien desde el lado de la ficción (en principio). Periodismo, desde las crónicas de sucesos más perentorias, y policial, 
desde las tramas demoradas en personajes y escenas, completarían la parte oscura de esa realidad contemporánea que no deja de producir nuevos miedos y nuevas amenazas. De modo que este género sería un molde privilegiado (por el éxito de público, como una de las razones principales) para reflejar las problemáticas sociales de las sociedades modernas. No deja de ser una feliz coincidencia (o quizás algo más que eso) que Leonardo Padura se haya dedicado tanto al periodismo como a la escritura de ficción policial.

En el caso del cubano, es precisamente el carácter turbio del género policial el que permite elaborar cierta crítica sobre La Habana, o al menos contraponer una ciudad distinta al relato oficial de la Revolución. Parte de la recepción de Padura en Europa ha querido ver en sus textos una crítica directa hacia el sistema político nacido de la Revolución y hacia los gobiernos de Fidel y Raúl Castro; sin embargo, el autor siempre ha defendido que su literatura iba más allá de una mera crítica política. David Becerra argumenta que el éxito de su literatura proviene de una (calculada) ambigüedad: mientras en el interior es premiado y reconocido como uno de los grandes escritores (Premio de la Crítica 2011 por El hombre que amaba a los perros, otorgado por el Instituto Cubano del Libro, y Premio Nacional de Literatura 2012), en el exterior ha sido aupado por las grandes editoriales, pertenecientes a grandes grupos de comunicación, precisamente por su carácter "disidente", o rebajando los términos más bien "crítico". No obstante, Padura siempre ha lamentado cualquier asociación directa entre su literatura y su posicionamiento personal con respecto al régimen cubano:

Tengo un ensayo que se llama "Yo quisiera ser Paul Auster" por una entrevista a Paul Auster que leí. El entrevistador no le preguntaba más que por béisbol, cine y literatura. ¡Vaya hombre! Las tres cosas que me gustan y no hacen más que preguntarme por economía cubana, por futurología... ¿Qué pasará en Cuba, Padura? (en Alemany)

Ante la asociación directa entre crítica social y disidencia al castrismo, Padura responde en términos literarios:

¿Se imagina escribiendo una novela sobre los cuadros de la Revolución? Una novela
de tirano a la antigua...
Creo que no. Tendría que ser una intriga política o una novela satírica y no soy muy
bueno para eso. En la novela de Trotski (El hombre que amaba a los perros) sí que
había algo de intriga política pero es que Trotski era político desde que se levantaba
de la cama. Yo ya sé que lo mío es contar las cosas desde el conflicto entre la sociedad
y el individuo. (en Alemany)

De modo que sería conveniente para la crítica evitar tal asociación. En mi opinión, el retrato social de La Habana que realiza Leonardo Padura en sus novelas parte de la especificidad del género negro, nacido para sacar a la luz la parte oscura del entramado social, pero no desde una disidencia ni explícita ni implícita. Padura

$111 \frac{\text { Revista Iberoamericana, Vol. LXXXV, Núm. 269, Octubre-Diciembre 2019, } 1271-1288}{\text { ISSN 0034-9631 (Impreso) }}$ 
ofrece al lector una variedad tal de voces, de hablas y de discursos que la realidad se revela compleja, trabada y necesariamente parcial, lejos de todo dogmatismo (revolucionario o contrarrevolucionario). Esta apelación al género para explicar los términos de la crítica social no resta ni mérito ni valentía en la literatura de Padura; de hecho, como explica Paula Martínez, Padura se distancia con el policial cubano realizado (y premiado por las instituciones culturales) en la isla en los años setenta y ochenta, caracterizado por alumbrar:

novelas de escasa o nula calidad literaria, utilizadas como instrumento de ideologización del pueblo cubano. Los detectives siempre son perfectos y virtuosos representantes del orden mientras que los criminales son seres abyectos que se oponen a la revolución. Los "buenos", gracias a su fe revolucionaria y a la ayuda del pueblo cubano, siempre ganan. (256)

Padura habría conseguido revitalizar el género en la isla, poniéndolo en la órbita del policial en Europa o en los Estados Unidos, es decir, sin negarle ninguna de las características propias del género y evitando caer en la propaganda subliminal de un contexto político determinado. Es interesante, en cambio, profundizar en la especificidad de la crítica social que presenta su literatura; en estos términos explica Padura su retrato habanero:

Uno de los grandes problemas de Cuba ha sido el gasto moral de estos años: la pérdida de valores, el deterioro del contrato social. En Cuba está la solidaridad pero está también, cada vez más, el egoísmo, el escepticismo... La palabra que usaríamos en Cuba es chusmería. (en Alemany)

Del mismo modo lo han visto estudiosos como Alex Martín Escribà y Javier Sánchez Zapatero, para los cuales el escritor cubano se habría valido de la reciente historia cubana para desplegar todas las características generales del género negro:

La aparición del teniente investigador Mario Conde coincide cronológicamente con la debacle ideológica y la posterior caída del socialismo europeo a principios de la década de los noventa. Estos acontecimientos son aprovechados por Padura para crear un nuevo tipo de literatura policial. Para llevarla a cabo, el escritor cubano ejerce una función de cronista literario e investigador periodístico. (55)

El escepticismo será el ingrediente fundamental de la representación social de la capital cubana; el desencanto será el motor del retrato contemporáneo de la sociedad habanera: 
Este cansancio viene reflejado por el desencanto a medida que transcurren sus historias, un desencanto que en el caso del escritor cubano se convierte en dolor y padecimiento al hablar de su ciudad. Las leves tramas de sus novelas no son más que excusas para presentar frescos económicos, sociales y políticos de Cuba en estos últimos años. (55)

Como en el resto de novelas de la saga de Mario Conde, el investigador por excelencia de Leonardo Padura, Herejes (2013) radiografiará la ciudad y su gente partiendo de ese mismo ambiente de escepticismo y desencanto. Sin embargo, la combinación de diferentes planos históricos en la novela (siglo XVII, años treinta y cuarenta del siglo XX y siglo XXI) establecerán paralelismos que permitirán una reflexión en torno a los sentidos de la derrota y de la libertad. En efecto, Herejes está compuesto de tres historias principales en tres tiempos históricos concretos, cada uno de los cuales resuena en los otros dos.

De forma somera, el primero se desarrolla en Ámsterdam entre 1643 y 1648 y cuenta la historia de Elías Ambrosius, aprendiz de pintor en el taller de Rembrandt, quien debe escapar de la ciudad camino de Polonia como un fugitivo, no por los movimientos antisemitas del momento en toda Europa, sino precisamente ante la condena de herejía de la propia comunidad judía por pintar.

La segunda historia se desarrolla en La Habana a partir de la llegada del transatlántico S. S. Saint Louis en 1939 lleno de refugiados alemanes de confesión judía, cuyo permiso de entrada al puerto fue denegado por las autoridades cubanas y posteriormente estadounidenses y canadienses, obligando así a los judíos a regresar a la Alemania nazi. El pequeño Daniel Kaminsky y su tío Joseph Kaminsky observan la escena, aterrados porque en el buque viajan sus familiares, y a partir de ese momento deberán iniciar una vida en La Habana hasta que en 1958 Daniel se instale en Miami.

El tercer plano de la acción se sitúa entre el año 2007 y 2009. Un descendiente de Daniel Kaminsky se pone en contacto con el investigador Mario Conde para averiguar la propiedad de un cuadro del taller de Rembrandt que está a punto de ser subastado y que podría ser propiedad de su familia, cuyas propiedades les fueron arrebatadas durante su huida de la Alemania nazi. De este modo, los tres relatos quedan conectados levemente por un objeto (el retrato que Rembrandt hiciera a un joven judío), y la investigación de su autoría y propiedad será el motor de la narración que conectará los tres planos históricos, a través de Elías Kaminsky (descendiente de Daniel Kaminsky y por lo tanto heredero de la obra de arte) y el detective Mario Conde. La conexión sirve a su vez, como decía, para reflexionar sobre los conceptos de libertad, sacralidad o derrota en distintas fases históricas, pero siempre bajo la misma esencia humanista.

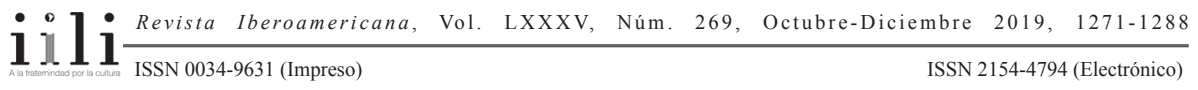


2. “Lo QUe HA PASAdo CONTIGO NADA MÁs SE PUEDE VER COMO UNA DERROTA”. 1643-1648

Las claves de toda interpretación alrededor de estos conceptos, extrapolable a los otros planos narrativos, se encuentra en la historia de Elías Ambrosius y su maestro Rembrandt. El paralelismo más evidente entre este momento y este relato con la historia de Daniel Kaminsky se encontraría en el contexto antisemita en que se desarrollan las acciones y que acaban por condenar a los personajes a la "derrota". Ámsterdam se describe en Herejes como una ciudad privilegiada para los judíos del XVII; mientras en el resto de Europa las persecuciones y expulsiones habían sido feroces, se había establecido en la ciudad holandesa una comunidad judía muy significativa. En la novela se describen sagas familiares instaladas allí, como la de Daniel, los círculos sociales de la comunidad, en cuyo centro se situaba la religión, así como los saberes, valores y costumbres. Sin embargo, será la propia Ley judía la que condene al protagonista: el mayor deseo de Elías Ambrosius es el de convertirse en pintor, bajo la tutela del maestro de la pintura flamenca Rembrandt, tan afamado en la época como devastado al final de sus días por la vejez, la pobreza y la muerte de sus hijos. Para la Ley judía, al entregarse al arte de la pintura Elías habría violado el segundo mandamiento, incluso al haber posado como modelo en un retrato del maestro holandés cuyo parecido con Jesucristo lo convertía en doblemente herético. El proceso y la condena obligan al joven judío a escapar de Ámsterdam e instalarse como un fugitivo en Polonia, de donde huirán siglos después, en los prolegómenos de la Segunda Guerra Mundial, los propietarios del famoso retrato.

En su proceso de formación vital, como si de una educación sentimental se tratase, Elías Ambrosius se desenvolverá en un ambiente rígido: el de las costumbres ortodoxas judías, practicadas por sus miembros como signo identitario y de reconocimiento en una sociedad con distintas confesiones religiosas que despiertan recelo mutuamente. Su pasión por la pintura, en primer lugar, así como su concepto de lo sagrado, en segundo, chocarán con esa rigidez. A partir de ese choque con la Ley de Jehová, el joven Ambrosius reflexionará junto a su maestro sobre qué significa realmente la libertad y cuáles son las amenazas reales para la realización del individuo:

Siempre habrá unos iluminados dispuestos a apropiarse de la verdad y a tratar de imponerle una verdad a los demás... No te conmino a que hagas nada, solo a que pienses: la libertad es el mayor bien del hombre y no practicarla, cuando resulta posible practicarla, es algo que Dios no nos puede pedir. Renunciar a la libertad sí constituye un pecado, casi una ofensa a Dios. (235)

Una de las grandes controversias entre el judaísmo y el cristianismo, y aun dentro del propio cristianismo, deriva del concepto de "libertad"y de "libre albedrío": mientras la ortodoxia judía sí afirma una determinación divina, el cristianismo entiende que es 
el individuo quien a través de sus acciones en la tierra se salva o se condena (según el catolicismo) o lo salva o lo condena el propio Dios (según el protestantismo) en la vida eterna. Los impulsos de realización del joven Ambrosius se enfrentan a los preceptos religiosos de una manera frontal; es aquí donde radica lo peligroso de las palabras de Rembrandt al asociar el "pecado" o la "ofensa a Dios" a la "privación de libertad" y defendiendo la libertad del hombre dentro de la religión.

Elías Ambrosius desarrollará su pasión y su talento artístico, y por oposición a los preceptos religiosos (que define el terreno de las prohibiciones) considerará la pintura como el terreno de la libertad y su práctica como un acto creador:

Elías Ambrosius tuvo un vislumbre de aquel misterio cuando su mano, obedeciendo un mandato que parecía provenir de una fuente ubicada mucho más allá de su conciencia y de sus miedos, grabó sobre su superficie impoluta el primer trazo de lo que sería el ojo. [...] El misterio, lo supo en ese instante, se llamaba poder: el poder de la Creación, el impulso de la trascendencia, la fuerza de la belleza que ninguna potestad podría vencer. (241)

Ambrosius establece así una correspondencia entre arte y libertad que va mucho más allá: la belleza del arte, junto a la libertad del artista, guiará el acto hacia la trascendencia, como si se tratara de una nueva Creación (con mayúsculas del autor). Y además, el impulso creador vendrá de una inspiración o de una fuerza situada "mucho más allá de su conciencia". La asociación de este acto artístico con la libertad, con la creación y con la trascendencia otorgará un carácter mesiánico al arte, que se enfrentará al oscurantismo de la ley religiosa.

En ese instante estaba descubriendo al fin por qué había decidido poner todo en el fuego y lanzarse a pintar: [...] [por] la certeza de que con un pincel, unos pigmentos y una superficie propicia, podía disfrutar del poder de crear una vida inadvertida para mucha gente pero que él era capaz de ver y, poseyendo las armas con las cuales lo dotara el Maestro, de reflejar, con pasión, emoción y belleza. (302)

En ese proceso de formación, el joven Ambrosius descubrirá también los placeres del cuerpo y del encuentro sexual. Lejos de acatar la doctrina religiosa al respecto, el joven judío no reprimirá sus impulsos sexuales, sino que iniciará una gozosa exploración de su sexualidad con su amante Mariam Roca. La atención dedicada al cuerpo durante el Renacimiento y el Barroco (de cuyos postulados es digno heredero Rembrandt), así como su estudio médico o su culto en el campo del arte, fueron terminantemente proscritos por las confesiones monoteístas. La sexualidad carnal o artística (y aun científica) sin el objetivo de la procreación era considerada un peligro moral y era motivo de condena eterna; no obstante, para Elías Ambrosius esos primeros encuentros sexuales se le revelaban como sagrados:

$111 \frac{\text { Revista Iberoamericana, Vol. LXXXV, Núm. 269, Octubre-Diciembre 2019, } 1271-1288}{\text { ISSN 2154-4794 (Electrónico) }}$ 


\begin{abstract}
"Sí, esto es lo sagrado", se dijo cuando sintió cómo, luego de un breve forcejeo con el virgo, su cuerpo se deslizaba dentro de las entrañas de Mariam Roca. Ella, después de la ruptura, que le provocó la molestia de un dolor sobre el cual ya estaba advertida, abrió los ojos, tragó aire, mientras devoraba hacia sus entrañas el pene circuncidado que ocupaba con ambición su espacio propicio de mujer, dándole el mayor sentido a la vida. [...] Adiestrado por las lecturas bíblicas, Elías Ambrosius tuvo la suficiente lucidez para ejecutar la estrategia de Onán y desconectarse, para eyacular sus simientes fuera del pozo de la joven. Sabía que antes de darse al goce pleno sería preciso romper las copas con las que se recordaban las ceremonias tradicionales celebradas por sus antepasados en el demolido Templo de Jerusalén. Por ahora debía conformarse con aquella revelación de lo sagrado, sin pretender eternizarla con el milagro de la procreación. (283-84)
\end{abstract}

Las remitencias entre lo sexual y lo sagrado en este fragmento son muy elocuentes. La sexualidad sin fines reproductivos es condenada por la ortodoxia judía (y católica) pero a la vez permite el acceso del joven a un tipo de revelación elevada, placentera y al mismo tiempo carnal y trascendente. Por supuesto, esta subversión del concepto de lo sagrado, que encierra una llamada a la libertad sexual (dentro de una convencionalidad entre lo masculino y lo femenino, nunca entre miembros del mismo sexo), sumaría una herejía más al cómputo de lo condenable en Elías Ambrosius.

Tras el descubrimiento de su actividad pictórica y del retrato mesiánico de Rembrandt, los jueces acusan al joven de herejía. La acusación trae consigo el rechazo y la exclusión social: "alguno de los judíos que lo conocían [...] pasaban de largo como si hubiera perdido su corporeidad. Elías sabía que muchos reaccionaban de tal modo por convicción, pero otros respondían de esa manera bajo la presión mezquina del miedo" (326-27), el abandono de su familia y el abandono de su país. Tal concepto de libertad, ligado al arte, a la creación y a un nuevo concepto de lo sagrado, condenará al aprendiz de pintor al destierro y a la huida hacia Polonia.

Lo que ha pasado contigo nada más se puede ver como una derrota... Y lo peor es que no se puede culpar a nadie. Ni a ti por haberte atrevido a desafiar ciertas leyes, ni a tu hermano Amós y los rabinos por querer juzgarte y condenarte: cada uno está haciendo lo que cree que debe hacer, y tienen muchos argumentos para fundamentar sus decisiones. Y eso es lo peor: que algo horrible parezca normal para algunos... Lo que más me entristece es comprobar que deben ocurrir historias como la tuya [...] para que los hombres por fin aprendamos cómo la fe en un Dios, en un príncipe, en un país, la obediencia a mandatos supuestamente creados para nuestro bien, pueden convertirse en una cárcel para la sustancia que nos distingue: nuestra voluntad y nuestra inteligencia de seres humanos. (330)

El abanico de la fe se abre en las palabras de despedida del maestro: la obediencia ciega a los mandatos de un Dios, de un príncipe o de un país pueden llevar al hombre a

$111 \frac{\text { Revista Iberoamericana, Vol. LXXXV, Núm. 269, Octubre-Diciembre 2019, }}{1271-1288}$ 
negar su humanidad. Se entiende entonces que la lectura del relato de Elías Ambrosius, con su fe en la libertad artística, creadora y sagrada, se extiende más allá de la religión, en concreto a la política ("un príncipe") o a la nación ("un país").

\section{3. “Aquella isla BendeCida POR El SOL”. 1939, AÑOS CUARENTA Y CINCUENTA}

La historia de Elías Ambrosius se entrelaza, como decía, con otras dos. El relato de la llegada del transatlántico Saint Louis es, en cambio, el que abre la novela con su trágico final, y es el que narrativamente sirve de puente entre las diferentes historias. La escena de la llegada del barco y su posterior regreso a Hamburgo, tras habérsele denegado el permiso de entrada a los refugiados en Cuba, Estados Unidos y Canadá, remite a las persecuciones o expulsiones de judíos de otro tiempo (como la de Elías Ambrosius). A la vez conecta con la historia contemporánea de Cuba, al retratar el ambiente de la capital de mitad de siglo que dio lugar al triunfo de la Revolución, momento en el que sucede toda la investigación de Mario Conde y de Elías Kaminsky alrededor del cuadro de Rembrandt.

El personaje fundamental de esta segunda historia es el niño Daniel Kaminsky, que llega a la ciudad de La Habana procedente de Cracovia; para más conexiones: Cracovia fue la ciudad adonde fue a parar en su exilio Elías Ambrosius. Bajo la tutela de su tío Joseph Kaminsky crecerá en ese nuevo entorno, asistirá a la tragedia del Saint Louis en el puerto sabiendo que allí viajaba su familia más cercana, a la que no volverá a ver más, y allí pasará toda su juventud hasta que en 1958 se marche a Miami. La arquitectura de la novela de Padura permite delimitar a la perfección los distintos periodos históricos y adscribirlos a las peripecias de los personajes, puesto que el $1 \mathrm{de}$ enero de 1959 triunfará la Revolución cubana, que será el marco de las investigaciones (cincuenta años después) de Mario Conde y del hijo de Daniel Kaminsky, Elías Kaminsky.

Tras la tragedia del Saint Louis, y sabiéndose herederos de una persecución secular por motivos religiosos, los caminos de Daniel y de Joseph tomarán direcciones opuestas: mientras que este se encerrará en la religión como signo identitario dentro de una comunidad multicultural, aquel se irá distanciando cada vez más de los preceptos religiosos. La Habana aparece entonces como un nuevo oasis en medio del desierto, similar a la Ámsterdam de Rembrandt y Ambrosius:

La paz y concordia que se vivían en Cuba, donde ser judío o dejar de serlo no parecía importarle demasiado a nadie, donde habían venido a confluir polacos, alemanes, chinos, italianos, gallegos, libaneses, catalanes, haitianos, gentes de todos los confines, le entregó una plenitud que ni en sueños había imaginado ningún judío desde los tiempos remotos en que los sefardíes habían sido admitidos en Ámsterdam. (72)

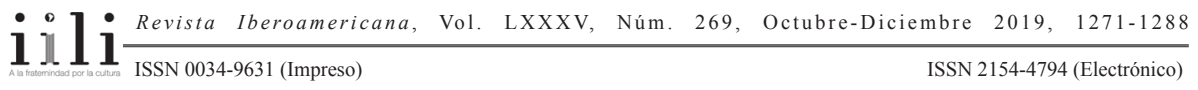


Este clima de apertura y mezcolanza permite a Daniel desvincularse de la ortodoxia judía practicada por su padre, e iniciar de algún modo el camino de formación seguido por Elías Ambrosius. Sin embargo, los sentimientos de pertenencia a la comunidad judía afloran con el nacimiento del Estado de Israel, conseguido tras desplegar "artimañas pacíficas y violentas y su capacidad de presión, económica y moral”, aunque sobre todo con los primeros ataques al nuevo país: “al fin y al cabo, algo más que un prepucio cortado lo identificaba con aquellas gentes. También estaba ligado a ellos por la sangre y, más aún, por la muerte" (77).

Más allá de la tolerancia religiosa, la parte más oscura de la capital habanera también quedará retratada:

Cierto era que la prosperidad del país y su democracia republicana, que permitían el progreso de los hebreos, debía convivir por esos años con el repunte de una de las peores lacras sociales: la corrupción. Tan visceral resultaba el afán de enriquecerse en el menor tiempo posible que dominaba a políticos, comerciantes, inversores, jefes militares y a policías y figuras más o menos públicas, que hasta se producían con cierta frecuencia violentas guerras de facciones, como las escenificadas por unos llamados "gángsters" cubanos. [...] En aquella isla bendecida por el sol, con todos los beneficios físicos para generar riqueza, donde se mezclaban culturas y razas, y todo el mundo cantaba y bailaba, también podía germinar el odio y la crueldad, incluso la más sádica, brotar el arribismo y las siempre sórdidas diferencias sociales y raciales y, sobre todo, manifestarse un mal que parecía haberse metido en el corazón de mucha gente del país: la envidia. (73)

A la Presidencia de la República de aquella isla bendecida por el sol había accedido mediante elecciones libres, inmediatamente después del 39, Fulgencio Batista, el dictador al que derrocará la Revolución. A partir de 1944, asumirá el poder Ramón Grau San Martín y a partir de 1948, Carlos Prío Socarrás, quien no llegaría a completar su mandato debido al golpe de Estado que daría Fulgencio Batista en 1952. El gobierno de Ramón Grau San Martín estuvo caracterizado por el aumento de la violencia en las calles, por el crecimiento del gangsterismo y la corrupción en el seno del gobierno: el Ministro de Educación, Juan Manuel Alemán, quien ideó el Bloque Alemán-Grau-Alsina para saquear las arcas públicas, fue cesado por el Presidente a causa de una moción de censura presentada en el Senado. Posteriormente la dictadura de Fulgencio Batista (1952-1958) mantuvo el sistema de corrupción política, lo que motivó el alzamiento revolucionario en todo el país. "Se acabó la diversión / llegó el Comandante y mandó a parar", cantaría Carlos Puebla, aludiendo a la corrupción de la dictadura y al ambiente viciado al que quisieron poner fin los postulados de la Revolución. Este fue el ambiente en el que creció Daniel Kaminsky, y a estos periodos prerevolucionarios alude el relato. 


\section{LA NUEVA GENERACIÓN SIN FE. 2007-2009}

El tercer plano temporal conduce al lector hasta La Habana de los años 2000. Superado el furor revolucionario y los grandes periodos por los que atraviesa el nuevo sistema (desde la consolidación del movimiento hasta el llamado "Periodo Especial", relatado en El hombre que amaba a los perros [2009] por ejemplo), Herejes retrata la nueva generación de jóvenes nacidos en los años noventa, en diálogo con la generación de Conde, nacidos y/o crecidos en los primeros años del triunfo de Fidel Castro (Mario Conde según los cálculos de la novela, habría nacido en 1953). La radiografía del estado emocional en que se encuentra la generación de Conde tras cincuenta años de revolución es muy elocuente:

A sus cincuenta y cuatro años cumplidos, Conde se sabía un paradigmático integrante de la que años atrás él y sus amigos calificaran como la generación escondida, los cada vez más envejecidos y derrotados seres que, sin poder salir de su madriguera, habían evolucionado (involucionado, en realidad) para convertirse en la generación más desencantada y jodida dentro del nuevo país que se iba configurando. Sin fuerzas ni edad para reciclarse como vendedores de arte o gerentes de corporaciones extranjeras, o al menos como plomeros o dulceros, apenas les quedaba el recurso de resistir como sobrevivientes. Así, mientras unos subsistían con los dólares enviados por los hijos que se habían largado a cualquier parte del mundo, otros trataban de arreglárselas de algún modo para no caer en la inopia absoluta o en la cárcel: como profesores particulares, choferes que alquilaban sus desvencijados autos, veterinarios o masajistas por cuenta propia, lo que apareciera. Pero la opción de buscarse la vida arañando las paredes no resultaba fácil y provocaba aquel cansancio sideral, la sensación de incertidumbre constante y derrota. (24)

Cansancio, incertidumbre y derrota (de nuevo encontramos la derrota en los personajes de Padura), supervivientes gracias a los dólares de los emigrados o al trabajo por cuenta propia: la crítica al castrismo nunca se realiza en Padura de modo directo, pero sí se retratan los efectos de más de cincuenta años de sistema en los personajes, evitando alusiones a la responsabilidad de los cuadros del régimen, o al bloqueo estadounidense o a la presión internacional. En cualquier caso, ese ambiente de derrota no es prototípicamente cubano, sino que se puede encontrar perfectamente en el personaje de Carvalho, el detective de las novelas negras de Manuel Vázquez Montalbán, por acudir a un ejemplo claro.

Aparte de la investigación sobre la peripecia del cuadro de Rembrandt, sobre cuya pista le pone Elías Kaminsky, el detective Conde deberá resolver la desaparición de la joven Judy. Este caso lo pondrá en diálogo con la nueva generación de jóvenes de la isla, que aparecerá por primera vez como parte del retrato habanero, muy alejado de los antiguos relatos sobre Cuba. El personaje de la joven es paradigmático para

$111 \frac{\text { Revista Iberoamericana, Vol. LXXXV, Núm. 269, Octubre-Diciembre 2019, } 1271-1288}{\text { ISSN 0034-9631 (Impreso) }}$ 
entender el cambio de paisaje que ofrece Padura: Judy es una joven que pertenece a la tribu urbana de los emos, que es lesbiana (aparentemente) y que ha desaparecido en circunstancias extrañas; los amigos especularán sobre si en realidad se ha suicidado o si se ha marchado a Italia con un amigo un tanto turbio gracias a los quinientos dólares que le ha robado a su madre. Pero además, Judy es hija de una familia de dirigentes cubanos, cuyo padre fue enviado a trabajar a Venezuela y que fue posteriormente despedido por realizar negocios ilegales en aquel país.

Las pesquisas que realizará Conde sobre el caso permitirá reflejar los pensamientos y sentimientos de esa nueva generación, que de algún modo desprecia la historia de su país y la manera de desenvolverse en ella por parte de la generación precedente:

-Una es emo porque es emo, no para divertirse-dijo la ema sentada a su lado-. Porque nos duele vivir en un mundo de mierda y no queremos saber nada de él. [...] Lo único que de verdad queremos es no tener una vida de mierda como la que tuviste y tienes tú. Segurito que eres un amargao porque nunca hiciste lo que querías hacer. Te tragaste todos los cuentos que te hicieron... por cobarde y por comemierda. Y total, ¿pa qué? ¿Qué ganaste con eso? (Herejes 358-59)

Mientras que la actitud de Conde, como representante de la generación que nació y creció en la Revolución, es de cansancio y derrota, la reacción del grupo de jóvenes nacidos en los noventa es airada. Desprecian los esfuerzos (revolucionarios o no) de sus mayores, y reniegan del mundo que han heredado, al tiempo que condenan la obediencia o la cobardía para haber cambiado las cosas. Pero ¿qué cosas? ¿Cuál es ese mundo que desprecian? Nunca será directamente el sistema revolucionario cubano.

Nosotros por lo menos no nos dejamos tratar como corderos, vamos a vivir la vida que nos da la gana y no le vamos a rendir pleitesía a nadie, ni hombre ni dios. No creemos en nada, no queremos creer... [...] No hablamos de libertad porque esa palabra los hijos de puta se la cogieron para ellos y la gastaron: ni eso queremos de ustedes... Agarramos lo que nos toca y ya... (360)

El fenómeno de las tribus urbanas no es exclusivo (obviamente) de Cuba; sin embargo, lo significativo no es que sea o no exclusivo, sino que también se dé en Cuba. Ese distanciamiento con el sistema de valores dominantes y convenciones sociales que practican los "emos" son un fenómeno global que florece en toda sociedad avanzada, desde Alemania hasta Reino Unido, España, Estados Unidos, etc. La aparición de los emos en Cuba y su reacción contra "el mundo" no implica una necesaria lectura contrarrevolucionaria de la novela; más bien, se inserta en un movimiento contracultural que extiende su protesta también hacia otro tipo de comunidades. ${ }^{1}$ Ahora bien, la tensión

1 Por ejemplo: Deseo de ser punk (2009) de Belén Gopegui, o Muchacha punk (1992) de Fogwill.

$111 \frac{\text { Revista Iberoamericana, Vol. LXXXV, Núm. 269, Octubre-Diciembre 2019, } 1271-1288}{\text { ISSN 2154-4794 (Electrónico) }}$ 
(y el sarcasmo) que genera en Conde a la hora de interpretar esa rebeldía es evidente: "Tanto que nos jodieron la vida con el sacrificio, el futuro, la predestinación histórica y un pantalón al año, para llegar a esto... ¿Vampiros, depresivos, masoquistas por cuenta propia? ¿Con este calor?” (349). Si bien la generación anterior estaba anclada en el descreimiento con respecto a la historia que les había tocado vivir, esta nueva generación se caracteriza por un rechazo frontal hacia toda forma de compromiso dentro de un proceso de alienación histórica; conviene insistir entonces en esta incomprensión mutua entre generaciones. El narrador, en cambio, sí consigue ver una lógica entre el proceso histórico de Cuba y el rechazo a las convenciones sociales del grupo de emos, a pesar de que en los diálogos de los jóvenes esta lógica no se manifieste de manera tan explícita:

Conde pensó que tal vez empezaba a comprender lo incomprensible: aquellos adolescentes estaban cansados de su medio ambiente. Sin embargo, no parecían dispuestos a hacer algo más que autodecorarse, emborracharse y marginarse cada noche para solucionar aquel estado de profunda fatiga, sin preocuparse demasiado por encontrar un camino de salida que no fuese la autoalienación. [...] Los emos eran los nietos de un avasallante cansancio histórico y los hijos de dos décadas repartida a conciencia, seres despojados de la posibilidad de creer, apenas empeñados en evadirse hacia un rincón que les pareciera lo más propio posible, tal vez hasta inaccesible para todos los que estaban fuera de aquel círculo mental y físico. (356)

No se trata de una pérdida de la fe revolucionaria, como pudiera sentir Conde y sus contemporáneos, sino un rechazo total de la realidad. $\mathrm{O}$ un proceso de mayor envergadura cultural que el mero rechazo a la política de Fidel o de Raúl Castro, y que enlazaría con otros fenómenos globales de indignación (Martínez Rubio).

[A]unque parezcan un grupo reducido, esos jóvenes están expresando un sentimiento generacional bastante extendido. Son el resultado de una pérdida de valores y categorías, del agotamiento de paradigmas creíbles y de expectativas de futuro que recorre a toda la sociedad, o a casi toda... [...] El margen entre el discurso político y la realidad se ha abierto demasiado, cada uno anda por su lado, sin mirarse, aunque debería ser el discurso quien observara la realidad y se redefiniera... (Herejes 431-32)

Esta distinción intergeneracional me parece significativa, del mismo modo que me parece significativo el reflejo de una serie de elementos prohibidos por la (en otro tiempo) ortodoxia revolucionaria: homosexualidad, tatuajes, piercings, drogas, contacto con extranjeros, nueva moda... pero también MP4, zapatillas Converse, Blackberry, elementos pertenecientes a la sociedad de consumo propia de los países capitalistas, entre los que Cuba no se contaría. Herejes iría más allá de la representación anterior propuesta por el propio Leonardo Padura, quien se había preocupado por ofrecer al

$111 \frac{\text { Revista Iberoamericana, Vol. LXXXV, Núm. 269, Octubre-Diciembre 2019, } 1271-1288}{\text { ISSN 0034-9631 (Impreso) }}$ 
lector (nacional y extranjero) un rumor de voces bien diversas, una polifonía ruidosa y democrática que invalidara cualquier discurso unívoco y que permitiera el reflejo de pensamientos distintos y de voces y hablas distintas (incluso a nivel lingüístico), como bien ha estudiado Paula García Talaván:

Podemos distinguir las de ciertos grupos sociales que de una u otra manera son o
han sido marginados en Cuba -homosexuales, intelectuales, escritores, artistas, la
comunidad china, la chino-cubana, la africana y la afrocubana, santeros, practicantes
de diversos ritos religiosos, gente de "vida alegre", chivatos y delincuentes-y la de
ciudadanos corrientes que, no entrando directamente en ninguno de estos grupos, han
visto reducido su campo de posibilidades económicas, culturales y de expresión como
consecuencia de algunas medidas adoptadas por el gobierno revolucionario. Junto
a ellas, aparecen las voces de algunos miembros de los Comités de Defensa de la
Revolución, las de numerosos policías, las de ciertos cargos políticos, principalmente
de las altas esferas, y las de ladrones de guante blanco que han sabido aprovechar las
fallas del sistema para enriquecerse a su costa; todas representan, en mayor o menor
medida, el discurso oficial establecido en Cuba a partir de la llegada de la Revolución
en 1959. (García Talaván 168)

Padura refleja una realidad habanera diferente a la esperable en un sistema comunista; la literatura en este caso actúa de espejo y de resorte para configurar una nueva sociedad aperturista:

Tras la enorme crisis económica que ha sufrido el país, el gobierno se ha visto obligado a abrir un espacio a la reflexión y a la crítica y a relajar ciertos niveles de censura, haciendo posible que la religión o la orientación sexual no sean motivos oficiales de discriminación social. La variedad de su procedencia nos da una idea de las tensiones que existen en la Cuba contemporánea y, puestos a dialogar, estos discursos influyen en la transformación del mismo contexto que los hace posibles. (García Talaván 175)

En definitiva, la representación que Padura ofrece sobre la ciudad de La Habana se traza sobre una doble tensión: por un lado, el descreimiento de la generación "revolucionaria" hacia su pasado, tras la caída del horizonte utópico, el trabajoso oficio de vivir y la pérdida de fe en el horizonte utópico; por otro, y esto es lo significativo, el descreimiento de la nueva generación "posrevolucionaria" que, aun habiendo asistido a un proceso efectivo de apertura política, no encuentra motivos para el compromiso social o no encuentra razones en las que depositar su fe, y que a su vez se manifiesta en consonancia con una actitud generacional global, no solo encuadrada en unos límites geográficos concretos. El diagnóstico de este grupo de jóvenes no diferiría esencialmente del diagnóstico que el filósofo Gilles Lipovetsky realizara al observar los conflictos y actitudes en las sociedades posindustriales, ligadas a lo que él denominaba La era el vacio (1986), El imperio de lo efímero (1990) o El crepúsculo del deber (1994):

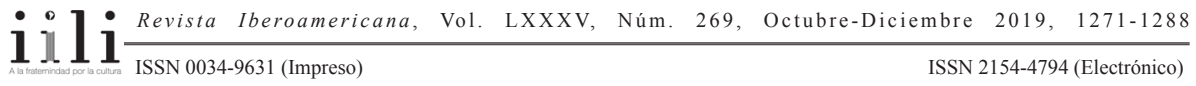


No nos adherimos sin reservas a la idea de progreso de las conciencias; en realidad las Luces avanzan, aunque mezcladas indisociablemente con su contrario [...]. En conjunto, las personas están más informadas aunque menos estructuradas, son más adultas pero más inestables, menos ideologizadas pero más tributarias de las modas, más abiertas pero más influibles, menos extremistas pero más dispersas, más realistas pero más confusas, más críticas pero más superficiales, más escépticas pero menos meditativas. (El imperio 18-19)

Pero, ¿en qué consiste la libertad que reclaman los personajes de la novela de Padura? La pregunta será clave para resolver esa doble tensión, y deberán contestarla ambas generaciones. Para la de Judy, Yadine o Yovani tendrá mucho que ver con no hacer lo que dictan sus mayores: "Porque estoy cansado de que me digan lo que tengo que hacer y cómo tengo que ser" (Herejes 383). Para la de Conde, será una batalla constante que ganar cada día:

\begin{abstract}
¿Sabes lo que yo tengo que hacer para tener un celular? Pues jugármela todos los días con policías de verdad, que existen, y mucho... Sabe Dios de dónde tu padre, tu madre o el bugarrón que te coge el culo sacan el dinero para mantenerte, vestirte y pagarte tus pujos. Así que déjate de comer mierda y de hacerte el puro y el hereje. Y si de verdad quieres deprimirte, oye lo que te voy a decir ahora: jese pullover de Dolce y Gabbana que tienes puesto es más falso que un billete de dos pesos...! ¿Quieres más trigo para deprimirte? Pues óyeme bien: ¡nunca vas a ser libre! ¿Y sabes por qué? Pues facilito: porque la libertad no te la dan si te escondes en tu rincón. (360-61)
\end{abstract}

Y resuenan en estas palabras las mismas que dijera Elías Ambrosius ante su maestro Rembrandt:

Mi abuelo, el jajám Bel Israel y usted han sido lo mejor que me ha sucedido, porque los tres, cada uno a su manera, me enseñaron que ser un hombre libre es más que vivir en un lugar donde se proclama la libertad. Me enseñaron que ser libre es una guerra donde se debe pelear todos los días, contra todos los poderes, contra todos los miedos. (319)

Mientras el concepto de "libertad" de los jóvenes se expresa en la novela en forma de lamento, el concepto de "libertad" de sus mayores (y aun de sus antepasados) se expresa en forma de sentencia o enseñanza: la libertad no remite a un estado de cosas o a una configuración formal de la sociedad de tal o cual modo, sino que más bien remite a una actitud de lucha en la vida. La libertad no sería, en última instancia, un entorno dado (ni democrático ni revolucionario), sino una actitud de combate frente a los miedos y frente a los numerosos poderes que nos limitan (políticos, económicos, sociales). El final de la novela aclara lo que para el narrador (compilador de todas las perspectivas de todo los personajes en la novela) significaría la libertad. Es significativo

$111 \frac{\text { Revista Iberoamericana, Vol. LXXXV, Núm. 269, Octubre-Diciembre 2019, } 1271-1288}{\text { ISSN 0034-9631 (Impreso) }}$ 
también el paralelismo que establece entre Ambrosius, Conde y Judy, fundiendo en sus rostros y sus ojos el mismo lamento por la opresión y la misma lucha por la libertad:

Detrás de los ojos de Mario Conde, en su mente, estaban abiertos los ojos del joven judío E. A., aprendiz de pintor, muerto hacía tres siglos y medio, posiblemente siguiendo, como tantos hombres en tantos sitios y a lo largo de los siglos, la estela de otro autoproclamado mesías y salvador, capaz de prometerlo todo para terminar revelándose como un farsante enfermo con la des del poder, con la avasallante pasión del dominio de otros hombres y sus mentes. Aquella historia a Conde le sonaba demasiado familiar y cercana. Y pensó que tal vez, en sus búsquedas libertarias, en algún momento Judy Torres había estado más próxima que mucha gente a una desoladora verdad: ya no hay nada en qué creer, ni mesías que seguir. Solo vale la pena militar en la tribu que tú mismo has elegido libremente. Porque si cabe la posibilidad de que, de haber existido, incluso Dios haya muerto, y la certeza de que tantos mesías hayan terminado convirtiéndose en manipuladores, lo único que te queda, lo único que en realidad te pertenece, es tu libertad de elección. Para vender un cuadro o donarlo a un museo. Para pertenecer o dejar de pertenecer. Para creer o no creer. Incluso, para vivir o para morirte. (513)

La "libertad de elección" se define en términos cotidianos, insisto, más allá de macroestructuras políticas y macrofísica o microfísica del poder en el sentido foucaultiano. Las últimas cuatro frases subordinadas finales aluden a las distintas acciones que ha relatado a lo largo de la novela: "vender un cuadro o donarlo", es la decisión que debe tomar Elías Kaminsky una vez el juez dicte a quién pertenece el cuadro de Rembrandt; "pertenecer o no pertenecer", es la decisión de los jóvenes con respecto a su tribu urbana o a su sociedad, pero también la de Elías Ambrosius o la de Daniel Kaminsky con respecto a la fe judía; "para creer o no creer", es la decisión de Elías, Daniel (en términos religiosos) o de Conde y su generación (en términos políticos), que han perdido la fe en el mandato histórico de la Revolución; y finalmente, "para vivir o para morirte", en clara alusión a la muerte de la joven Judy. Este tipo de libertad, acosada por la historia, que se manifiesta antes en una actitud que en un estatus, será el hilo interpretativo fundamental que entrelace los tres relatos y los tres tiempos, y la única certeza a la que se podrán aferrar los nuevos habaneros, carentes de una fe concreta, deseosos de pertenecer y de reconocerse como comunidad. El futuro los espera con todos sus peligros y todas sus posibilidades. 


\section{BiBLIOGRAFÍA}

Alemany, Luis. "Leonardo Padura: 'Me quedé en Cuba para escribir"'. El Mundo. 11 marzo 2015. <http://www.elmundo.es/cultura/2015/03/11/54fdcd73268e3eb91a 8b4577.html>. 1 sept. 2015.

Arjona, David. "Panorámica del género negro". El Cultural.9jul. 2008. <www.elcultural. com/noticias/letras/panoramica-del-genero-negro/502884>. 25 junio 2018.

Becerra, David. "El caso Padura y el tiro por la culata del imperio". Crónica Popular. 15 jun. 2015. <http://www.cronicapopular.es/2015/06/el-caso-padura-y-el-tiropor-la-culata-del-imperio/>. 1 sept. 2015.

Berman, Marshall. Todo lo solido se desvanece en el aire: la experiencia de la Modernidad. México: Siglo XXI, 2004.

Fogwill, Rodolfo. Muchacha punk. Barcelona: Planeta, 1992.

García Talaván, Paula. "Transgresión de un silencio obligado: la polifonía discursiva de Leonardo Padura”. Kamchatka: Revista de Análisis Cultural 2 (2013): 165-177. $<$ https://ojs.uv.es/index.php/kamchatka/article/view/3156>. 1 sept. 2015.

Gopegui, Belén. Deseo de ser punk. Barcelona: Anagrama, 2009.

Lipovetsky, Gilles. El crepúsculo del deber. La ética indolora de los nuevos tiempos democráticos. Barcelona: Anagrama, 1994.

La era del vacio. Ensayos sobre el individualismo contemporáneo. Barcelona: Anagrama, 1986.

El imperio de lo efímero. La moda y su destino en las sociedades modernas. Barcelona: Anagrama, 1990.

Martín Escribà, Àlex y Javier Sánchez Zapatero. "Una mirada al neopolicial latinoamericano: Mempo Giardinelli, Leonardo Padura y Paco Ignacio Taibo II". Anales de literatura latinoamericana 36 (2007): 49-58.

Martínez, Paula. "Leonardo Padura, entre la realidad y la ficción”. El género negro: el fin de la frontera. Martín Escribà, Àlex y Javier Sánchez Zapatero, coords. Santiago de Compostela: Andavira, 2012. 255-60.

Martínez Rubio, José. "Identidades enlazadas. Memoria, democracia e indignación: diálogos intergeneracionales en la España del siglo XXI". Olivar. Revista de Literatura y Cultura Españolas 14/20 (2013): 245-67.

Padura, Leonardo. Herejes. Barcelona: Tusquets, 2013.

El hombre que amaba a los perros. Barcelona: Tusquets, 2009.

Resina, Joan Ramon. El cadáver en la cocina. La novela criminal en la cultura del desencanto. Barcelona: Anthropos, 1997.

$111 \frac{\text { Revista Iberoamericana, Vol. LXXXV, Núm. 269, Octubre-Diciembre 2019, } 1271-1288}{\text { ISSN 0034-9631 (Impreso) }}$ 
Palabras clave: Leonardo Padura - neopolicial social - Herejes - generación posrevolucionaria cubana - libertad de elección

Recibido: agosto 2016

Aceptado: $\quad$ mayo 2017

11] Revista Iberoamericana, Vol. LXXXV, Núm. 269, Octubre-Diciembre 2019, 1271-1288 